\title{
Role of Healthy Work Environments in Sustainability of Goal Achievement; Ethical Leadership, Intention to Sabotage and Psychological Capital in Jordanian Universities
}

\author{
Shadi Mohammad Altahat*(D) and Tarik Atan \\ Department of Business Administration, Faculty of Economics and Administrative Sciences, \\ Cyprus International University, 99258 Lefkosa, North Cyprus; tatan@ciu.edu.tr \\ * Correspondence: shadialtaha@yahoo.com
}

Received: 10 September 2018; Accepted: 1 October 2018; Published: 4 October 2018

check for updates

\begin{abstract}
Background: Long-term competitiveness and sustainability of goal achievement are constantly being sought out by organizations. This study examined the link between ethical leadership, intention to sabotage, and psychological capital in Jordanian universities and how they provide a healthy environment conducive to goal achievement sustainability. The literature indicated gaps in knowledge regarding the correlation between these variables in non-western countries, which this study intends to fill. The study drew from social learning theory and self-control theory. (2) Methods: Data was obtained by collecting survey questionnaires from a sample of 376 employees in different universities in the north of Jordan, and was analyzed with Statistical Package for the Social Sciences (SPSS) and Structural Equation Modeling. (3) Results: A significant and direct negative relationship was found between both ethical leadership and psychological capital on employees' intention to sabotage. Also, a significant and direct positive effect was found between ethical leadership and psychological capital. Furthermore, it was found that psychological capital mediated the relationship between ethical leadership and employees' intention to sabotage. (4) Conclusions: Leaders have a critical role in increasing employee psychological capital and decreasing intention to sabotage. Many implications indicated by the study's findings, both theoretical and practical, were discussed.
\end{abstract}

Keywords: ethical leadership; intention to sabotage; psychological capital; human resource management; Jordan

\section{Introduction}

In present days, the competitive global environment obliges us to choose an effective leadership style to reduce the rate of attrition and achieve the goals of the organization. According to [1], effective leadership styles affect employee performance and productivity. There are many leadership styles, such as Transformational Leadership, Transactional Leadership, Laissez-Faire Leadership, Autocratic Leadership, Democratic Leadership, Servant leadership, Charismatic Leadership, and Ethical leadership [2-5].

All styles of leadership contain features like honesty, reliability, fairness, integrity, concern for others, and acting ethically, but this is only one part of ethical leadership, the other part, known as the moral manager, influences the ethical behavior of followers by concentrating on more transactional efforts. Therefore, ethical leaders stress the significance of ethics to followers, use positive and negative reinforcement to effect desired changes in behavior, and act as ethical role models for subordinates [6]. 
The topic of ethical leadership continues to grow in importance as business scandals continue to make international headlines [7-9]. According to [10], ethical leadership refers to behaviors that consist of appropriate norms. It has also been defined as "the demonstration of normatively appropriate conduct through personal actions and interpersonal relationships, and the promotion of such conduct to followers through two-way communication, reinforcement, and decision-making" [11] (p. 120). It is considered to be "essential leadership behavior" [12] (p. 22).

Many previous researchers have shown the importance of the effects of ethical leadership on attitudes, fostering positive behaviors [9,12-14], followers' job satisfaction and dedication [11] (p. 117), fostering ethical behaviors in organizations and inspiring them [15], and decreasing deviant behavior [16-20].

Brown and Treviño [16] proposed followers would show pro-social behavior increases and counterproductive and deviant behavior decreases in the presence of ethical leadership. Studies have so far focused on leadership behaviors, but have ignored the expectations of followers and the contextual environment [2], which have been taken into consideration in this study.

Work and service sabotage is a major problem and is believed to be a source of other issues for organizations today. Trust is an important component between the employee and employer, distrust and negative feelings have been associated with decreased performance and increased service sabotage [17].

According to [21] businesses in the USA lose about $\$ 200$ billion per year from sabotage or misbehavior. Service sabotage is considered the actual act of sabotage, whereas intention to sabotage is more related to the likelihood of being involved in these actions. Intention to sabotage has been defined as the negative attitude or the destructive state of mind, which is distinguished by withdrawal, alienation, and destruction. It also aims to disable or negatively impact a persistent service in the organization [22].

The significant impact of sabotage found in previous studies and the costs associated with businesses make further study of the subject warranted [21]. However, the effect of ethical leadership on employees' intention to sabotage remains an overlooked issue, according to [22]. The phenomenon of intention to sabotage is mostly not well understood and therefore not recognized as a matter requiring attention [23]. The direct effect between ethical leadership and intention to sabotage may be complex, but it may be a needed mechanism to decrease the intention to sabotage. Examining this relationship in different cultures (Arab Islamic culture) was strongly encouraged by previous research [24].

Regarding Jordanian organizational culture, Jordan's culture is characterized by static, bureaucratic, and tribalistic tendencies. It is also very religious and has fewer opportunities for democratic expression [25]. As a part of the Arab world, Jordan's culture and that of its organizations is similar to other countries in the region, and differs from the West. Arab managers are less likely to communicate intentions behind their decisions or give their subordinates increased authority. This lack of information sharing causes top-level managers to be isolated from the rest of the organization [26,27]. In addition to its mostly classical Arabic heritage, Jordan was also colonized by the Greeks, Romans, and British which has left a lasting influence on its work culture. Jordanians are predominantly Muslim; Islamic law emphasizes ethicality and equality in the treatment of people, regardless of their background or socioeconomic status. This cultural climate remains the central pillar in Jordanian organizational climate. The tribal system of Jordan is unique in its influence due to Jordan's small size and population, to the extent that tribes formed hundreds of years ago still have great influence on society and business. In spite of that and the relative lack of resources in the country, the government has been increasing efforts to modernize the country and its organizations and management systems [28].

Jordanian universities are an imperative part of Jordan's education sector, and their leaders realized the importance of ethical work and ethical leadership. These ethics are vital to build people's trust in Jordanian national institutions, both locally and internationally. Leaders and managers in Jordanian universities have been shown to be highly ethical and professional in hiring and performance evaluation, where the main drive behind leaders' engagement was fairness, integrity, 
and objectivity [29]. In recent times, campus violence, misconduct, and service sabotage by Jordanian university students and employees have been increasing. Some studies have been undertaken to study this phenomenon, but to this day, the underlying reasons are still not that clear and the results of these studies have not been as effective as hoped in stopping this phenomenon [30,31]. The researcher has taken this into account, and is trying to look into the novel effects of ethical leadership on such phenomenon.

Social learning theory [32] and self-control theory [33] were relied on to explain psychological mechanisms and the process of how ethical leadership influences employee's intention to sabotage through the mediation of psychological capital. Based on these theories, external factors could enhance psychological capital and decrease the employee's intention to sabotage. The empirical study of the effects of ethical leadership on intention to sabotage has been limited; a recent study from [34] was applied in Turkey, and reported that service sabotage was decreased by ethical leadership. A few empirical studies were in favor of these claims, particularly in developing countries like Jordan.

Thus, the purpose of this paper is to investigate possible ethical leadership influences on employees' intention to sabotage, and other underlying mechanisms between ethical leadership and employees' intention to sabotage with mediating roles of psychological capital in Jordanian universities, as depicted in Figure 1.

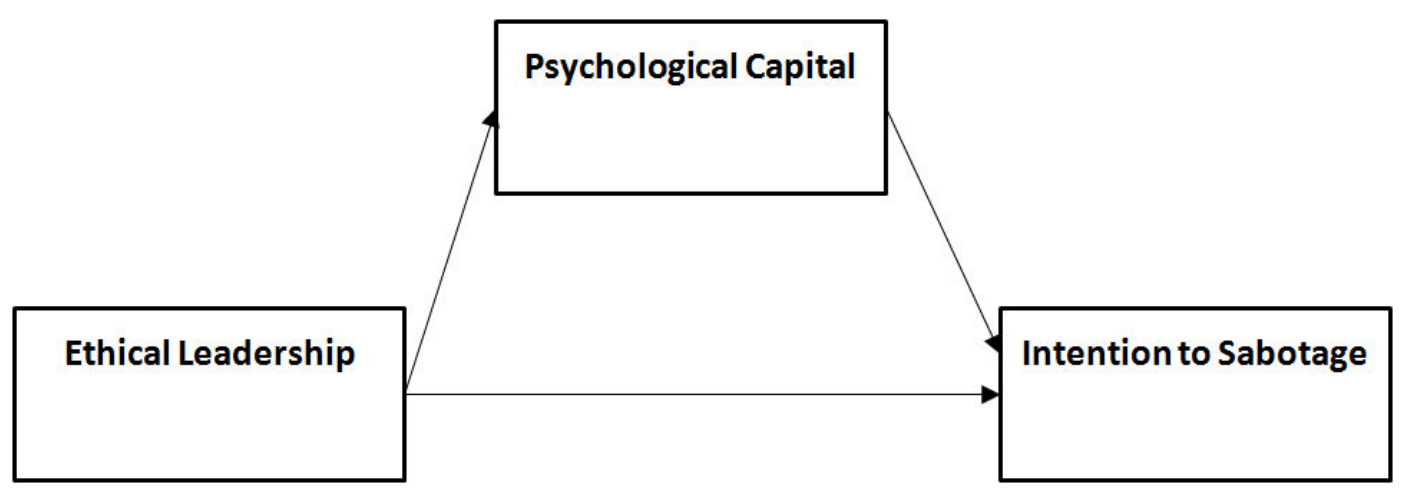

Figure 1. Research conceptual model.

Research on ethical leadership and intention to sabotage are briefly summarized in the following sections, then several hypotheses are introduced regarding the relationships between ethical leadership, intention to sabotage, and psychological capital.

\subsection{Theoretical Background and Hypotheses}

\subsubsection{The Relationship between Ethical Leadership and Intention to Sabotage}

Brown et al. [11] reported that little research has been done on the ethical dimension of leadership. While several styles of leadership have emerged (e.g., transformational and authentic leadership), most of the recent attention had been paid to ethical leadership as part of these styles, not as an independent style $[9,10,12-14,16]$. Brown et al. [11] constructed an instrument to assess ethical leadership and examine its predictive validity for significant staff results.

The resulting ten-item Ethical Leadership Scale (ELS) is a common measure of ethical leadership behavior. They reflect both dimensions of an ethical leader (being a moral manager and a moral person), which are predicted to affect the behavior and attitudes of their followers through the demonstration of ethical leadership behavior [16].

Ethical leadership consists of several behaviors consistently found in previous research. Kalshoven, Hartog and De Hoogh [35] (p. 51) proposed that ethical leaders are characterized by "fairness, integrity, ethical guidance, people orientation, power sharing, role clarification, and concern for sustainability". Kalshoven et al. [35] also developed a multi-dimensional Ethical Leadership at Work (ELW) questionnaire. 
Many previous researchers were interested in investigating the role of ethical leadership in reducing misbehavior and unethical actions in organizations [16-19]. Unethical behaviors occurring within organizations have been reported in alarming statistics. But in spite of the high occurrence of these behaviors, most of them are still unnoticed or not reported [19].

One of the destructive consequences of employee misbehavior was defined as sabotage behavior [34]. Previous research has found four factors that may lead to employee sabotage behavior: individual factors, group and role factors, organizational factors, and environment factors [36]. Abu Bakar and Arasli [22] argued the importance of measuring intention to sabotage first, instead of measuring service sabotage. They stated that "instead of measuring service sabotage, intention to sabotage would provide the management with intelligence in advance, and they can take necessary precautions to prevent the misbehavior" (p. 1268).

Social learning theory can be used to understand how ethical leaders might influence employees' intention to sabotage. According to social learning theory, people learn by watching and recreating values and behaviors they think are credible or attractive [32,37]. In organizations, leaders are often the examples in organizations that employees use to determine acceptable and appropriate behavior. Employees learn what is expected by both direct experience and by observing others; when leaders show ethical behaviors, their employees imitate these actions [32,37]. Mayer et al. [19] (p. 8), stated, "Ethical leaders, in particular, are expected to enforce practices, policies, and procedures that serve to uphold ethical conduct". This is reinforced by leaders rewarding or punishing the ethical or unethical actions of employees, respectively. Furthermore, ethical leaders make ethical standards for followers "guiding good behavior (consistent with the standards) and deterring misconduct (that would violate the standards)" [38] (p. 958). Thus, such models and standards would increase employees' positive behavior and may decrease their intention to sabotage.

Based on this review of the definition of ethical leadership and the intention to sabotage, the following hypothesis is assumed:

Hypothesis 1. Ethical leadership negatively predicts intention to sabotage in Jordanian universities.

\subsubsection{The Relationship between Ethical Leadership and Psychological Capital}

Many previous researchers empirically showed that employee positive ethical behavior was directly affected by factors of ethical leadership [9,12-14]. This study attempted to further explore the possible relationship between ethical leadership and psychological capital.

According to many previous researchers, psychological capital has four elements: efficacy, hope, optimism and resilience $[39,40]$. Hope is "a positive motivational state based on an interactively derived sense of successful (a) agency (goal-directed energy) and (b) pathways (planning to meet goals)" [41] (p. 287). Motivation and willpower are increased when managers show confidence in employees [42]. While self-efficacy was defined as "the individual's conviction or confidence about his or her abilities to mobilize the motivation, cognitive resources or courses of action needed to successfully execute a specific task within a given context" [43] (p. 66), creative self-efficacy is the belief that one has confidence in one's ability to produce creative outcomes and results [44,45]. Mehmood [46] conducted a study at Capital University of Science and Technology in Islamabad, Pakistan to examine the role of ethical leadership in determining creative self-efficacy of academic organizations. The results found a positive relationship between ethical leadership and creative self-efficacy.

Resilience also was defined as "the capacity to rebound or bounce back from adversity, conflict, failure or even positive events, progress and increased responsibility" [47] (p. 702). This is seen in the ability to change and adapt to unpredictable situations and finding solutions. Ethical leaders give employees opportunities to predict and overcome obstacles by developing plans to circumvent them.

The last component of psychological capital is optimism; a realistic, flexible, and dynamic construct [48] that refers to a positive explanatory method in which positive events are ascribed 
to personal, permanent and ubiquitous causes, while negative events are interpreted in terms of external and short-lasting factors and on a case-by-case basis. While similar to hope, it is distinguished by persistence and pervasiveness, which are key dimensions in people's explanations of events [49].

Furthermore, ethical leaders care about the feelings of employees and make them feel respected and invested in outcomes. Secondly, they are effective communicators and build personal relationships. Also, managers who conduct effective, regular, and comprehensive communications with employees, while encouraging and supporting their participation in decision-making and management, and also providing them with opportunities and the foundation or starting point for career development and are persistently exemplified by the idea of psychology-based management through the entire process of human resource management, will eventually solidify the emotional commitment of employees to the organization that develops their psychological capital.

Based on this review of the definition of ethical leadership and psychological capital, the following hypothesis was assumed:

Hypothesis 2. Ethical leadership positively predicts the employee's psychological capital level in Jordanian universities.

\subsubsection{The Relationship between Psychological Capital and Intention to Sabotage}

Investigating the role of psychological capital in reducing unethical misbehavior in organizations has received little attention by researchers [50,51]. However, some researchers have found that psychological capital influences a variety of variables like job satisfaction [52,53], absenteeism [54], employee performance [53], employee well-being [55], and organizational commitment [52,53].

Many studies have tried to reveal factors that may trigger the service staff's sabotage behavior [17,36]. Chi et al. [17] found that daily negative moods of employees predicted higher service sabotage, while emotional stability would reduce the relationship between daily negative mood and service sabotage.

The present study uses self-control theory $[33,56]$ to explain the relationship between employees' psychological capital level and their intention to sabotage. Self-control is defined as a person's ability to control their impulses, behaviors, emotions, and performances in order to accomplish personal interests and goals [56,57]. The self-control perspective asserts that a positive psychological capital leads to work engagement and organizational commitment [58] and decreases negative behaviors such as the intention to sabotage [59].

Moreover, individuals with a positive psychological state of development are characterized by self-efficacy (confidence), optimism, resilience (flexibility), and hope [60]. They are more confident in handling stress-inducing work, have a more positive outlook of themselves, and do not allow negative emotions to control their thoughts and behavior [61]. Furthermore, when employees are emotionally stable, they are less likely to let negative moods distract them and are able to cope with any impulsive intentions that result from experiencing negative moods at work [62,63], which detracts from the effect that daily negative mood might have on service sabotage.

Therefore, the following hypothesis is proposed:

Hypothesis 3. Employee psychological capital level negatively predicts daily intention to sabotage.

\subsubsection{Mediating Role of Psychological Capital between Ethical Leadership and Intention to Sabotage}

Previous research showed that employees with higher self-esteem showed more of an effect from ethical leadership on their organizational behavior [13,55]. Khuong and Duc [13] investigated the factors of ethics-based leadership that affected employees' virtuous-ethical behavior. They found that employees' behavior was affected by ethical leadership factors, and employees with higher 
self-esteem showed more of an effect from ethical leadership on their own organizational virtuous behavior. This result demonstrated that ethical leadership decreases negative and unethical behavior in employees $[13,19]$. This result also shows that followers may react differently to ethical leaders based on their own attributes, so the results found when studying ethical leadership depend as much on the attributes of the followers as the leader. Van Gils et al. [20] argued that the effects of ethical leadership on followers is a result of interaction between the leader and the followers, rather than the leader's behavior alone.

Thus, according to the self-control framework [56], employees with high psychological capital levels in the current study were expected to show better self-control, which would mediate the effects of ethical leadership on the employee's intention to sabotage. This study posits that the direct effects of ethical leadership on the employee's intention to sabotage are revealed through enhanced employee psychological capital levels, which encourages followers to exhibit an extra commitment at work. Therefore, the following hypothesis was proposed:

Hypothesis 4. Psychological capital mediates the relationship between ethical leadership and the employees' intention to sabotage.

\section{Materials and Methods}

\subsection{Study Design}

This study utilized a quantitative method approach with survey questionnaires to provide in-depth coverage of the issues examined in Jordanian universities.

\subsection{Measurements}

A self-administered survey was developed consisting of the following variables: Ethical leadership, Psychological capital, and Intention to sabotage.

Ethical leadership was measured by an adapted Ethical Leadership Scale (ELS) questionnaire of [11], an (ELS) questionnaire was produced, providing a measure of overall ethical leadership. The five-point Likert scale was used in this study, ranging from " $1=$ strongly disagree" to " $5=$ strongly agree" for employee's self-ratings of their manager's ethical behavior. For example, "My boss listens to what employees have to say".

Psychological capital was measured with a 24-item questionnaire adapted from the original 24-item PCQ [60]; containing four sub-scales: hope, work self-efficacy, optimism, and resilience which were discussed above. This part was also measured by a five-point Likert scale questionnaire, ranging from " 1 = strongly disagree" to " $5=$ strongly agree", with the employee's self-rating of their own behavior. For example, "I feel confident in analyzing a long-term problem to find a solution".

Intention to sabotage was measured with an adapted 11-item questionnaire of [22]. In this variable, the employees rated the frequency of their immediate behaviors on a five-point Likert scale from " $1=$ never seen" to " 5 = always". For example, "I think about withdrawing my effort and energy and enacting flexible service rules because of rude customers".

All parts were translated into Arabic and then back-translated into English (translation back-translation procedure) [64,65].

To ensure validity, the final instrument was given to a panel of three bilingual professors of business to check the clarity of the items and the accuracy of the translation, creating face validity. Feedback was also used to clarify some words and items to ensure they were suitable for the Jordanian context. The final survey consisted of two sections: the first section being the demographic variables captured, (including gender, age, company type, and education), and the second section introducing several items regarding relationships among ethical leaderships (10 items), intention to sabotage (11 items), and psychological capital (24 items). 


\subsection{Participants and Procedures}

The instrument was first tested with a pilot survey distributed to 15 respondents. The survey population was about 9000 employees in different universities; three public and four private, in the north of Jordan. According to Steven Thompson's equation, the sample size that would adequately represent the population is 368 [66]. Thus, 450 questionnaires were distributed personally by the researcher to employees in different universities. The probability sampling method was adopted for this study.

Of the 450 given to participants, 402 questionnaires were completed with an $89 \%$ response rate. The final analysis used 376 questionnaires due to missing data. The survey was conducted in Arabic and the answers were translated into English before it was analyzed with SPSS and Structural Equation Modelling (SEM) with AMOS. The participants were given the time they needed. Some of the questionnaires were collected on the same day and others the day after, as some employees were busy with their work.

A survey package was prepared for each employee which contained a cover letter from the researchers asking for their participation, a short overview of the study's purpose, the importance of the study for their university, and the Ministry of Higher Education \& Scientific Research in Jordan's approval. Confidentiality was also guaranteed to reduce the risk of common method bias (CMB) as suggested by [67].

Demographics: $37 \%$ of the participants were female, $58.2 \%$ of them had organizational tenure more than ten years, $46.3 \%$ had some college degree, $36.7 \%$ had a bachelor's degree, $9.6 \%$ had higher degrees, and $51.1 \%$ of the employee participants were deployed in public universities.

\section{Results}

\subsection{Descriptive Statistics}

The standard deviations, means, and interrelations among the used variables are demonstrated in Table 1. As predicted, ethical leadership was negatively correlated with the intention to sabotage $(\mathrm{r}=-386)$ and positively correlated to psychological capital $(\mathrm{r}=0.455)$. Also, psychological capital was negatively correlated with the intention to sabotage $(r=-438)$. Thus, $\mathbf{H 1}, \mathbf{H} 2$, and $\mathbf{H} 3$ received preliminary support from these results.

In addition to that, Table 1 shows Cronbach's alpha $(\alpha)$, which was used to test the reliability and found to be above the threshold of 0.60 . Also, the convergent validity of the measurement model found in composite reliability (CR) was also above the threshold of 0.70 on the scale items [68]. Average variance extract (AVE) was also above the threshold of 0.50 [69].

Table 1. Standard deviation, means, correlations and reliability among variables.

\begin{tabular}{lccccc}
\hline \multicolumn{1}{c}{ Variables } & $\mathbf{1}$ & $\mathbf{2}$ & $\mathbf{3}$ & $\mathbf{M}$ & SD \\
\hline 1. Ethical Leadership & 1 & $-386^{* *}$ & $0.455^{* *}$ & 4.14 & 0.582 \\
2. Intention to sabotage & $-386^{* *}$ & 1 & $-438^{* *}$ & 1.74 & 0.731 \\
3. Psychological capital & $0.455^{* *}$ & -438 & 1 & 3.93 & 0.549 \\
Composite reliability (CR) & 0.954 & 0.968 & 0.974 & & \\
Cronbach's $\alpha$ & 0.952 & 0.957 & 0.973 & & \\
Average variance extract (AVE) & 0.681 & 0.732 & 0.61 & & \\
\hline
\end{tabular}

$\mathrm{N}=376,{ }^{* *}$ correlations were shown to be significant at $p<0.001$.

Furthermore, Confirmatory Factor Analysis (CFA) was used to investigate factor loadings [70]. The results shown in Table 2 indicate that all factor loadings were acceptable and significant; the factor loadings ranged from 0.59 to 0.95 , for more details see Figure A1 in Appendix A. 
Table 2. Confirmatory Factor Analysis (CFA) psychometrics properties of measures.

\begin{tabular}{|c|c|c|c|c|}
\hline Constructs & Code of Item & Loading & $\mathbf{M}$ & SD \\
\hline \multirow{10}{*}{ Ethical Leadership } & ETH-L-1 & 0.947 & 4.20 & 0.672 \\
\hline & ETH-L-2 & 0.942 & 4.17 & 0.683 \\
\hline & ETH-L-3 & 0.861 & 4.22 & 0.676 \\
\hline & ETH-L-4 & 0.695 & 4.15 & 0.671 \\
\hline & ETH-L-5 & 0.871 & 4.15 & 0.71 \\
\hline & ETH-L-6 & 0.762 & 4.06 & 0.755 \\
\hline & ETH-L-7 & 0.720 & 4.06 & 0.685 \\
\hline & ETH-L-8 & 0.601 & 4.09 & 0.711 \\
\hline & ETH-L-9 & 0.879 & 4.13 & 0.704 \\
\hline & ETH-L-10 & 0.897 & 4.16 & 0.683 \\
\hline Constructs & Code of Item & Loading & $\mathbf{M}$ & SD \\
\hline \multirow{24}{*}{ Psychological Capital } & PSY-EFF-1 & 0.915 & 3.89 & 0.669 \\
\hline & PSY-EFF-2 & 0.881 & 3.96 & 0.711 \\
\hline & PSY-EFF-3 & 0.717 & 3.93 & 0.697 \\
\hline & PSY-EFF-4 & 0.667 & 3.92 & 0.696 \\
\hline & PSY-EFF-5 & 0.811 & 3.93 & 0.714 \\
\hline & PSY-EFF-6 & 0.751 & 3.90 & 0.693 \\
\hline & PSY-OPT-7 & 0.765 & 3.91 & 0.712 \\
\hline & PSY-OPT-8 & 0.858 & 3.94 & 0.675 \\
\hline & PSY-OPT-9 & 0.780 & 3.93 & 0.697 \\
\hline & PSY-OPT-10 & 0.902 & 3.90 & 0.671 \\
\hline & PSY-OPT-11 & 0.723 & 3.91 & 0.688 \\
\hline & PSY-OPT-12 & 0.735 & 3.90 & 0.712 \\
\hline & PSY_HOP-13 & 0.697 & 3.94 & 0.676 \\
\hline & PSY_HOP-14 & 0.751 & 3.87 & 0.696 \\
\hline & PSY_HOP-15 & 0.623 & 4.02 & 0.783 \\
\hline & PSY_HOP-16 & 0.938 & 3.97 & 0.686 \\
\hline & PSY_HOP-17 & 0.695 & 3.95 & 0.674 \\
\hline & PSY_HOP-18 & 0.635 & 3.86 & 0.721 \\
\hline & PSY_RES-19 & 0.841 & 3.94 & 0.676 \\
\hline & PSY_RES-20 & 0.591 & 3.91 & 0.710 \\
\hline & PSY_RES-21 & 0.747 & 3.88 & 0.694 \\
\hline & PSY_RES-22 & 0.783 & 4.01 & 0.728 \\
\hline & PSY_RES-23 & 0.853 & 3.87 & 0.684 \\
\hline & PSY_RES-24 & 0.902 & 3.97 & 0.704 \\
\hline Constructs & Code of Item & Loading & $\mathbf{M}$ & SD \\
\hline \multirow{11}{*}{ Intention to sabotage } & Int-Sab-1 & 0.820 & 1.71 & 0.856 \\
\hline & Int-Sab-2 & 0.849 & 1.73 & 0.804 \\
\hline & Int-Sab-3 & 0.944 & 1.78 & 0.866 \\
\hline & Int-Sab-4 & 0.902 & 1.73 & 0.869 \\
\hline & Int-Sab-5 & 0.857 & 1.73 & 0.845 \\
\hline & Int-Sab-6 & 0.749 & 1.70 & 0.782 \\
\hline & Int-Sab-7 & 0.727 & 1.75 & 0.777 \\
\hline & Int-Sab-8 & 0.846 & 1.72 & 0.781 \\
\hline & Int-Sab-9 & 0.792 & 1.68 & 0.828 \\
\hline & Int-Sab-10 & 0.952 & 1.81 & 0.928 \\
\hline & Int-Sab-11 & 0.849 & 1.80 & 0.882 \\
\hline
\end{tabular}

\subsection{Hypothesis Tests}

\subsubsection{Measurement Model}

The CFA and SEM, with the AMOS program were used to test the proposed hypotheses and to verify the goodness of fit of the recommended and proposed model. The measurement model and hypothesized structural model were evaluated using the goodness of fit as shown in Table 3 [71]. 
Three latent factors were contained in the measurement model (ethical leadership, psychological capital, employee's intention to sabotage) and 45 indicators (10 items for ethical leadership, 24 items for psychological capital, and 11 items for employee's intention to sabotage). The measurement model showed a good fit, producing the following results: $\chi^{2}=1574.530, \mathrm{df}=923, \chi^{2} / \mathrm{df}=1.706, \mathrm{NFI}=0.92$, GFI $=0.84$, CFI $=0.96$, RMSEA $=0.43$ which can be seen in Table 3 .

Table 3. Goodness of fit for the model.

\begin{tabular}{ccc}
\hline Measurement Model & Structural Model & Cut-Off Points \\
\hline$\chi^{2}=1574.530$ & $\chi^{2}=1574.530$ & \\
Df $=923, p=0.000$ & Df $=923, p=0.000$ & $1=$ optimum fit [72] \\
GFI $=0.84$ & GFI $=0.84$ & $1=$ optimum fit [73] \\
NFI $=0.92$ & NFI $=0.92$ & $1=$ optimum fit [74] \\
CFI $=0.96$ & CFI $=0.96$ & Good fit $<0.08[70]$ \\
RMSEA $=0.043$ & RMSEA $=0.043$ & Good fit between 1 and 5 [75] \\
CMIN $/ d f=1.706$ & CMIN $/ d f=1.706$ & Good fit $<0.08[76]$ \\
SRMR $=0.339$ & SRMR $=0.0339$ & Does not affect study's data $<0.50[67]$ \\
CMP $=0.44$ & &
\end{tabular}

GFI: goodness-of-fit indices; CFI: comparative fit index; NFI: normed fit index; CMIN/df: relative $\chi^{2}$; RMSEA: root mean square error of approximation; SRMR: Standardized Root Mean Square Residual; CMB: Common method bias.

\subsubsection{Hypothesized Model}

After confirming that the measurement model demonstrated a good fit, the proposed structural model had been tested and showed a good fit (see Table 3), producing the following results: $\left(\chi^{2}=1574.530, \mathrm{df}=923, \chi^{2} / \mathrm{df}=1.706, \mathrm{NFI}=0.92, \mathrm{GFI}=0.84, \mathrm{CFI}=0.96, \mathrm{RMSEA}=0.43\right.$, SRMR $=0.0413$ ) [70]. Then, the partially mediated model was compared with a fully mediated model. The fully mediated model also provided a good fit to the data $\left(\chi^{2}=1593.617, \mathrm{df}=924, \chi^{2} / \mathrm{df}=1.725\right.$, $\mathrm{NFI}=0.919, \mathrm{GFI}=0.84, \mathrm{CFI}=0.96, \mathrm{RMSEA}=0.44, \mathrm{SRMR}=0.0607)$. Despite that, this model does not achieve any demonstrable improvement in fit over the partially mediated model, which indicates that ethical leadership has a meaningful and significant direct effect on employee's intention to sabotage when testing the partially mediated model, as will be discussed later. Thus, in accordance with [77]'s procedure, the partially mediated model is a better fitting model for investigating these data particularly.

The results presented in Table 4 confirmed that the path coefficient between ethical leadership and employee's intention to sabotage $(b=-0.386, p \leq 0.001)$ was negative and significant, and explains $R^{2}$ (intention to sabotage) $=15 \%$ of the variance (H1 was supported). In support of Hypothesis 2 , the result showed that ethical leadership influenced psychological capital $(b=0.455, p \leq 0.001)$, and explains $R^{2}$ (psychological capital $)=21 \%$ of the variance, so $\mathbf{H} \mathbf{2}$ was supported. Hypothesis 3 predicted that the impact of psychological capital on the employee's intention to sabotage $(b=-0.438, p \leq 0.001)$ was negative and significant, and explains $R^{2}$ (intention to sabotage) $=19 \%$ of the variance (H3 gained empirical support). Hypothesis 4 predicted that psychological capital mediates the relationship between ethical leadership and employee's intention to sabotage. The effect of ethical leadership on intention to sabotage decreased while also being significant and negative when psychological capital (the mediator variable) was added to the proposed model. Also the indirect effect of the relationship between ethical leadership and the employees' attention to sabotage was significant $(b=-0.153, p \leq 0.001)$. The total effect of the relationship between ethical leadership and the employees' intention to sabotage was significant $(b=-0.386, p \leq 0.001)$. So, the partially-mediated model was supported according to [77]'s procedure, thus Hypothesis 4 was supported. 
Table 4. Total, direct, and indirect effects of the research variables.

\begin{tabular}{ccccc}
\hline Exogenous Variables & Endogenous Variables & Total Effect & Direct Effect & Indirect Effect \\
\hline Ethical leadership & Intention to sabotage & -0.386 & -0.233 & -0.153 \\
Ethical leadership & Psychological capital & 0.450 & 0.450 & 0.000 \\
Psychological capital & Intention to sabotage & -0.341 & -0.341 & 0.000 \\
\hline
\end{tabular}

\section{Discussion}

All four hypotheses were supported. Ethical leadership was negatively related to intention to sabotage and positively related to psychological capital. Also, psychological capital was negatively related to employees' intention to sabotage. In addition to that, the findings suggest that psychological capital partially mediated the relationship between the employee's intention to sabotage and ethical leadership.

The first finding confirmed that ethical leadership has a negative and significant impact on employee's intention to sabotage, which is in accordance with earlier researchers and social learning theory which were discussed above $[16,18,19,22,34]$.

Furthermore, this study found that ethical leaders have a positive and significant impact on psychological capital. This is also consistent with the social learning theory and previous research. When managers show confidence in employees and have confidence in their abilities [45], it produces creative self-efficacy [46]. This also occurs when ethical leaders give the employees opportunities to predict and overcome obstacles while achieving their goals. Similarly, Mayer et al. [18] (p. 3) stated that "ethical leaders communicate the importance of ethics to subordinates, use rewards and punishments to encourage desired behavior, and serve as ethical role models for followers".

Moreover, the findings regarding the third hypothesis showed that psychological capital has a positive and significant impact on the employee's intention to sabotage. This is in line with the self-control theory $[33,56]$ and prior findings. The self-control perspective predicts that positive psychological capital increases confidence in dealing with stressful work, increases a positive self-view, and decreases the impact of negative emotions on thoughts and behaviors [61], which results in decreasing negative behaviors such as the intention to sabotage. Reduction of employees' intention to sabotage is of vital importance for organizations, universities in particular. The results from this research suggest that leaders and managers are critical in decreasing employee misconduct and intention to sabotage [59].

Previous research showed that employees who had higher self-esteem had higher effects from ethical leadership on their organizational behavior [13,55]. Furthermore, followers reacted more strongly to ethical leaders, which supports the idea that the effects of ethical leadership depend as much on the followers as on the leader [20]. According to the self-control framework [56], employees with high psychological capital levels present a better self-control capacity for buffering the positive effect of ethical leadership on the employee's intention to sabotage, which encourages followers to exhibit more commitment at work.

\section{Conclusions}

In conclusion, it is vitally important for organizations to reduce employee's intention to sabotage. The study found that the negative link between ethical leadership and intention to sabotage is stronger when followers have a higher psychological capital. Followers with a high psychological capital are more confident in dealing with stressful work, have a positive self-view, and their thoughts and behaviors aren't as impacted by negative emotions [61]. The results from this research suggest that leaders or managers play a critical role $[16,18]$ in creating psychological capital and decreasing employee misbehaviors and intention to sabotage in Jordanian universities. This creates a healthy work environment which helps organizations achieve their goals sustainably. 


\subsection{Implications}

These findings have several theoretical and practical implications. The findings can be used to better understand Jordanian universities' workplaces, help create healthier work environments by ensuring ethics training for managers, and contribute to several fields of organizational research, including organizational behavior, organizational development, and human resource management. This study underscores the relevance of ethical leadership as an outstanding leadership approach that needs to be learned and instilled in both burgeoning and experienced leaders.

The findings of this study could improve understanding and practices of the universities' organizational management of the employees' intention to sabotage, and encourage policies in the universities to deal with misbehavior. It also encourages them to promote ethical leadership in the selection process. Additionally, the recruiting process criteria could include leadership behaviors that inspire Jordanian employees' ethical behavior, which would also set the foundation for building the future of Jordanian ethical leaders in universities/organizations.

Another theoretical implication results from the supporting evidence of the valuable role of social learning theory and self-control theory in explaining how and why ethical leadership affects the employee's behavior in different universities/organizations. The present findings asserted that ethical leadership has a great influence on the employee's intention to sabotage.

\subsection{Limitations, Strength and Future Research Directions}

This research had its limitations, as do all studies. First, the research focused on the ethical leadership style only and did not include any data for other styles. This additional data would have provided better context and comparison to how the various styles affect intention to sabotage.

The proposed model was applied in Jordan, a single developing country. Thus, the findings should not be considered generalizable to other countries. Future research could extend the model so that it applies to other countries that share similar structures, cultures, and contexts and, in addition to those that do not, then this cumulative data could be compared to find geographic or regional differences.

Future research should consider this data on ethical leadership in Jordan, considering its social and cultural characteristics and exploring how Jordanian culture shapes leadership characteristics. Future research also might investigate factors that may moderate the relationship between ethical leadership and the employee's intention to sabotage, such as gender of leaders and employee, company type, and employee's work experience.

Despite these limitations, this study contributed to knowledge in the field of management by filling an endemic gap in the literature. Most research studies on ethical leadership are conducted using leaders as participants; prior researchers suggested that future research should explore the phenomenon of ethical leadership from the viewpoint of followers [78,79].

Author Contributions: Conceptualization, S.A. and T.A.; methodology, S.A.; validation, S.A. and T.A.; formal analysis, S.A.; investigation, S.A.; resources, S.A.; data curation, S.A.; Writing-Original draft preparation, S.A.; Writing-Review and editing, S.A. and T.A.; supervision, T.A.; project administration, S.A.

Funding: This research received no external funding.

Conflicts of Interest: The authors declare no conflict of interest. 


\section{Appendix A}

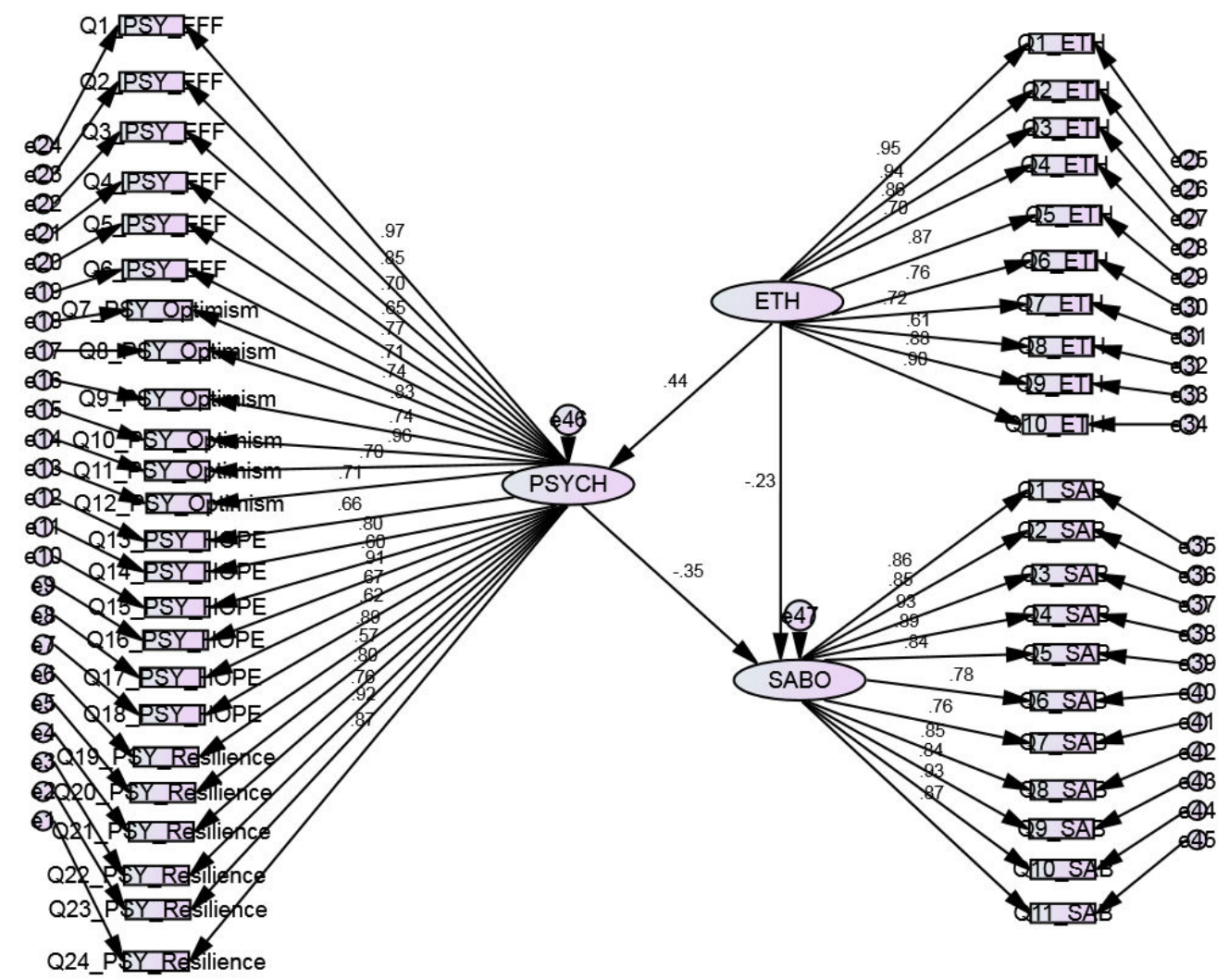

Figure A1. Loading factors and standardized estimates for regression weights.

\section{References}

1. Nanjundeswaraswamy, T.S.; Swamy, D.R. Leadership styles. Adv. Manag. 2014, 7, 57-62.

2. Copeland, M.K. The importance of ethics and ethical leadership in the accounting profession. Res. Prof. Responsib. Ethics Account. 2015, 61-98. [CrossRef]

3. Ho, S.Y.; Fu, H.J. The impacts of leadership styles on work performances and organizational innovations in the financial distress industry. Revista de Cercetare si Interventie Sociala 2018, 60, 25-38.

4. Khan, Z.A.; Nawaz, A.; Khan, I. Leadership theories and styles: A literature review. J. Resourc. Dev. Manag. 2016, 16, 1-7.

5. Yang, Z.; Zhu, J. Charismatic Leadership Behavior and Leadership Effectiveness: The Moderating Role of Subordinates' Emotional Intelligence and the Mediating Role of Psychological Empowerment. Revista de Cercetare si Interventie Sociala 2016, 55, 158-184.

6. Trevino, L.K.; Brown, M.E.; Hartman, L.P. A qualitative investigation of perceived executive ethical leadership: Perceptions from inside and outside the executive suite. Hum. Relat. 2003, 56, 5-38. [CrossRef]

7. Ciulla, J.B. Leadership ethics: Mapping territory. In Ethics the Heart of Leadership; Ciulla, J.B., Ed.; Preager Publishers: Westport, Ireland, 1998; pp. 3-25.

8. Kalshoven, K.; Den Hartog, D.N.; De Hoogh, A.H.B. Ethical leadership and follower helping and courtesy: Moral awareness and empathic concern as moderators. Appl. Psychol. Int. Rev. 2012, 62, 211-235. [CrossRef]

9. Schoonbeek, B. Ethical Leadership and the Influence on Organizational Citizenship Behavior: The Moderating Role of Job Autonomy and the Mediating Role of LMX. Master's Thesis, University of Amsterdam, Amsterdam, The Netherlands, 2012, unpublished.

10. Demirtas, O. Ethical leadership influence at organizations: Evidence from the field. J. Bus. Ethics 2015, 126, $273-284$. [CrossRef] 
11. Brown, M.E.; Treviño, L.K.; Harrison, D.A. Ethical leadership: A social learning perspective for construct development and testing. Organ. Behav. Hum. Decis. Process. 2005, 97, 117-134. [CrossRef]

12. Yıldı, H.; Yıldız, B. The effects of ethical leadership, servant leadership and leader-member exchange on compulsory citizenship behaviors. Int. Bus. Res. 2016, 9, 19-33. [CrossRef]

13. Khuong, M.N.; Duc, V.M. The effect of ethical leadership on employee's virtuous behavior: A study of marketing agencies in Ho Chi Minh City, Vietnam. J. Econ. Bus. Manag. 2015, 3, 832-839. [CrossRef]

14. Yidong, T.; Xinxin, L. How ethical leadership influence employees' innovative work behavior: A perspective of intrinsic motivation. J. Bus. Ethics 2012, 116, 441-455. [CrossRef]

15. Downe, J.; Cowell, R.; Morgan, K. What determines ethical behavior in public organizations: Is it rules or leadership? Public Adm. Rev. 2016, 76, 898-909. [CrossRef]

16. Brown, M.E.; Treviño, L.K. Ethical leadership: A review and future directions. Leadersh. Q. 2006, 17, 595-616. [CrossRef]

17. Chi, N.; Chang, H.; Huang, H. Can personality traits and daily positive mood buffer the harmful effects of daily negative mood on task performance and service sabotage? A self-control perspective. Organ. Behav. Hum. Decis. Process. 2015, 131, 1-15. [CrossRef]

18. Mayer, D.M.; Kuenzi, M.; Greenbaum, R.; Bardes, M.; Salvador, R. How low does ethical leadership flow? Test of a trickle-down model. Organ. Behav. Hum. Decis. Process. 2009, 108, 1-13. [CrossRef]

19. Mayer, D.M.; Kuenzi, M.; Greenbaum, R. Examining the link between ethical leadership and employee misconduct: The mediating role of ethical climate. J. Bus. Ethics 2010, 95, 7-16. [CrossRef]

20. Van Gils, S.; Van Quaquebeke, N.; van Knippenberg, D.; Van Dijke, M.; De Cremer, D. Ethical leadership and follower organizational deviance: The moderating role of follower moral attentiveness. Leadersh. Q. 2015, 26, 190-203. [CrossRef]

21. Lee, J.J.; Ok, C.M. Understanding hotel employees' service sabotage: Emotional labor perspective based on conservation of resources theory. Int. J. Hosp. Manag. 2014, 36, 176-187. [CrossRef]

22. Abu Bakar, M.A.; Arasli, H. Dear top management, please don't make me a cynic: Intention to sabotage. J. Manag. Dev. 2016, 35, 1266-1286. [CrossRef]

23. Estes, B.; Wang, J. Integrative Literature Review: Workplace Incivility: Impacts on Individual and Organizational Performance. Hum. Resour. Dev. Rev. 2008, 7, 218-240. [CrossRef]

24. Al-Araimi, M.F.S. The Relationship between the Full Range of Leadership Styles and Employees' Creative Performance in Civil Service Organizations: A Field Study of Omani Civil Service Managers. Ph.D. Thesis, The University of Manchester, Manchester, UK, 2012, unpublished.

25. Al-Rasheed, A. Features of traditional Arab management and Organization in the Jordanian business environment. J. Transit. Manag. Dev. 2008, 6, 27-53. [CrossRef]

26. Hofstede, G.; Minkov, M. Cultures and Organizations: Software of the Min, 3rd ed.; McGraw-Hill: New York, NY, USA, 2010.

27. Sabri, H. Socio-cultural values and organizational culture. J. Transit. Manag. Dev. 2004, 9, 123-145. [CrossRef]

28. Sawalha, I.; Meaton, J. The Arabic culture of Jordan and its impacts on a wider Jordanian adoption of business continuity management. J. Bus. Contin. Emerg. Plan. 2012, 6, 84-95.

29. Taamneh, M.; Athamneh, S.; AL Nsairat, B. The effect of administrators' work-related ethics on practicing human resource management functions at Jordanian universities. Int. J. Public Sect. Perform. Manag. 2017, 3. [CrossRef]

30. Abu-Nair, N.S. The phenomenon of the university violence and the role of universities in reducing the spread from the point of view of the faculty members in Jordanian universities. Dirasat. Educ. Sci. 2016, 43, 213-233. [CrossRef]

31. Al Majalie, A.A. The phenomenon of campus violence factors in light of the perceptions of graduate students at the university of Mutah. Jordan J. Soc. Sci. 2016, 3, 323-344. [CrossRef]

32. Bandura, A. Social Learning Theory; Prentice-Hall: Englewood Cliffs, NJ, USA, 1977.

33. Baumeister, R.F.; Vohs, K.D.; Tice, D.M. The strength model of self-control. Curr. Dir. Psychol. Sci. 2007, 16, 351-355. [CrossRef]

34. Yeşiltaş, M.; Tuna, M. The effect of ethical leadership on service sabotage. Serv. Ind. J. 2018, 1-27. [CrossRef]

35. Kalshoven, K.; Hartog, D.; De Hoogh, A. Ethical leadership at work questionnaire (ELW): Development and validation of a multidimensional measure. Leadersh. Q. 2011, 22, 51-69. [CrossRef]

36. Harris, L.C.; Ogbonna, E. Exploring service sabotage: The antecedents, types and consequences of frontline, deviant, anti service behaviors. J. Serv. Res. 2002, 4, 163-183. [CrossRef] 
37. Bandura, A. Social Foundations of Thought and Action; Prentice-Hall: Englewood Cliffs, NJ, USA, 1986.

38. Treviño, L.K.; Weaver, G.R.; Reynolds, S.J. Behavioral ethics in organizations: A review. J. Manag. 2006, 32, 951-990. [CrossRef]

39. Luthans, F. The need for and meaning of positive organizational behavior. J. Organ. Behav. 2002, 23, 695-706. [CrossRef]

40. Luthans, F.; Youssef, C.M. Human, social, and now positive psychological capital management: Investing in people for competitive advantage. Organ. Dyn. 2004, 33, 143-160. [CrossRef]

41. Snyder, C.R.; Irving, L.; Anderson, J. Hope and health: Measuring the will and the ways. In Handbook of Social and Clinical Psychology; Snyder, C.R., Forsyth, D.R., Eds.; Pergamon: Elmsford, NY, USA, 1991; pp. 285-305.

42. Walsh, K. Applying career concepts to strengthen the work-attitudes of service professionals. Serv. Ind. J. 2016, 36, 58-79. [CrossRef]

43. Stajkovic, A.D.; Luthans, F. Social cognitive theory and self-efficacy: Going beyond traditional motivational and behavioral approaches. Organ. Dyn. 1998, 26, 62-74. [CrossRef]

44. Rubio, C.; Osca, A.; Recio, P.; Urien, P.; Peiro, J.M. Work-family conflict, self-efficacy, and emotional exhaustion: A test of longitudinal effects. Revista de psicología del Trabajo y de las Organizaciones 2015, 13, 147-154. [CrossRef]

45. Tierney, P.; Farmer, S.M. Creative self-efficacy: Its potential antecedents and relationship to creative performance. Acad. Manag. J. 2002, 45, 1137-1148. [CrossRef]

46. Mehmood, S. Impact of Ethical Leadership on Creative Self Efficacy: Mediating Role of Ethical Orientation and Moderating Role of Supervisor Support for Creativity. Master's Thesis, Capital University of Science and Technology, Islamabad, Pakistan, 2017, unpublished.

47. Luthans, F. Positive organizational behavior: Developing and managing psychological strengths. Acad. Manag. Exec. 2002, 16, 57-72. [CrossRef]

48. Peterson, C. The future of optimism. Am. Psychol. 2000, 55, 44-55. [CrossRef] [PubMed]

49. Carver, C.S.; Scheier, M.F. Control processes and selforganization as complementary principles underlying behaviour. Personal. Soc. Psychol. Rev. 2002, 6, 304-315. [CrossRef]

50. Mortazavi, S.; Yazdi, S.V.S.; Amini, A. The role of the psychological capital on quality of work life and organization performance. Inst. Interdiscip. Bus. Res. 2012, 4, 206-217.

51. Zapf, D.; Einarsen, S.; Hoel, H.; Vartia, M. Empirical Findings on Bullying in the Workplace. In Bullying and Emotional Abuse in the Workplace; Einarsen, S., Hoel, H., Zapf, D., Cooper, C.L., Eds.; Taylor \& Francis: London, UK, 2003; pp. 103-126.

52. Larson, M.; Luthans, F. Potential Added Value of Psychological Capital in Predicting Work Attitudes. J. Leadersh. Organ. Stud. 2006, 13, 44-61. [CrossRef]

53. Luthans, F.; Avey, J.B.; Patera, J.L. Experimental analysis of a web-based training intervention to develop positive psychological capital. Acad. Manag. Learn. Educ. 2008, 7, 209-221. [CrossRef]

54. Avey, J.B.; Patera, J.L.; Wes, B.J. The implications of positive psychological capital on employee absenteeism. J. Leadersh. Organ. Stud. 2006, 13, 42-60. [CrossRef]

55. Avey, J.B.; Palanski, M.E.; Walumbwa, F.O. When leadership goes unnoticed: The moderating role of follower self-esteem on the relationship between ethical leadership and follower behavior. J. Bus. Ethics 2011, 98, 573-582. [CrossRef]

56. Tice, D.M.; Bratslavsky, E.; Baumeister, R.F. Emotional distress regulation takes precedence over impulse control: If you feel bad, do it! J. Personal. Soc. Psychol. 2001, 80, 53-67. [CrossRef]

57. Muraven, M.; Baumeister, R.F. Self-regulation and depletion of limited resources: Does self-control resemble a muscle? Psychol. Bull. 2000, 126, 247-259. [CrossRef] [PubMed]

58. Simons, J.C.; Buitendach, J.H. Psychological capital, work engagement and organisational commitment amongst call centre employees in South Africa. SA J. Ind. Psychol. 2013, 39, 1-12. [CrossRef]

59. Tice, D.M.; Bratslavsky, E. Giving in to feel good: The place of emotional regulation in the context of general self-control. Psychol. Inq. 2000, 11, 149-159. [CrossRef]

60. Luthans, F.; Youssef, C.M.; Avolio, B.J. Psychological Capital; Oxford University Press: Oxford, UK, 2007.

61. Barrick, M.R.; Mount, M.K. Select on Conscientiousness and Emotional Stability. In Handbook of Principles of Organizational Behavior; Locke, E.A., Ed.; Wiley: Hoboken, NJ, USA, 2000; pp. 15-28.

62. Barrick, M.R.; Mount, M.K. The Big Five Personality Dimensions and Job Performance: A Meta-Analysis. Pers. Psychol. 1991, 44, 1-25. [CrossRef] 
63. John, O.P.; Gross, J.J. Individual Differences in Emotion Regulation. In Handbook of Emotion Regulation; Guilford Press: New York, NY, USA, 2007; pp. 351-372.

64. Saunders, M.; Lewis, P.; Thornhill, A. Research Methods for Business Students, 5th ed.; Pearson Education: London, UK, 2009.

65. Brislin, R. Translation and content analysis of oral and written materials. In Handbook of Cross-Cultural Psychology: Methodology; Allyn \& Bacon: Boston, MA, USA, 1980; pp. 389-444.

66. Thompson, S. Adaptave cluster sampling. J. Am. Stat. Assoc. 1990, 85, 1050-1059. [CrossRef]

67. Podsakoff, P.; MacKenzie, S.; Lee, J.; Podsakoff, N. Common method biases in behavioral research: A critical review of the literature and recommended remedies. J. Appl. Psychol. 2003, 88, 879-903. [CrossRef] [PubMed]

68. Hair, J.; Anderson, R.; Tatham, R.; Black, W. Multivariate Data Analysis, 5th ed.; Prentice Hall: Upper Saddle River, NJ, USA, 1998.

69. Fornell, C.; Larcker, D. Evaluating structural equation models with unobservable variables and measurement error. J. Mark. Res. 1981, 18, 39-50. [CrossRef]

70. Browne, M.W.; Cudeck, R. Alternative ways of assessing model fit. In Testing Structural Equation Models; Sage: Newbury Park, CA, USA, 1993; p. 136.

71. Anderson, J.; Gerbing, D. Structural equation practice: A review and recommended two-step approach. Psychol. Bull. 1988, 103, 411-423. [CrossRef]

72. Tanaka, J.S.; Huba, G.J. A fit index for covariance structure models under arbitrary GLS estimation. Br. J. Math. Stat. Psychol. 1985, 38, 197-201. [CrossRef]

73. Bentler, P.M.; Bonett, D.G. Significance tests and goodness of fit in the analysis of covariance structures. Psychol. Bull. 1980, 88, 588-606. [CrossRef]

74. McDonald, R.P.; Marsh, H.W. Choosing a multivariate model: Non centrality and goodness of fit. Psychol. Bull. 1990, 107, 247-255. [CrossRef]

75. Marsh, H.W.; Hocevar, D. Application of confirmatory factor analysis to the study of self-concept: First- and higher-order factor models and their invariance across groups. Psychol. Bull. 1985, 97, 562-582. [CrossRef]

76. Hu, L.; Bentler, P.M. Cutoff criteria for fit indexes in covariance structure analysis: Conventional criteria versus new alternatives. Struct. Equ. Modeling A Multidiscip. J. 1999, 6, 1-55. [CrossRef]

77. Baron, R.M.; Kenny, D. Moderator-Mediator Variables Distinction in Social Psychological Research: Conceptual, Strategic, and Statistical Consider ations. J. Personal. Soc. Psychol. 1986, 51, 1173-1182. [CrossRef]

78. Heres, L.; Lasthuizen, K. What's the Difference? Ethical Leadership in Public, Hybrid and Private Sector Organizations. J. Chang. Manag. 2012, 12, 441-466. [CrossRef]

79. Lei, H.-S.; Lai, C.-F.; Chen, C.-C. How Does Project Supervisor Maintain Sustainability of Project Members? A Study from Leadership Perspective. Sustainability 2018, 10, 2785. [CrossRef] 